\title{
INVESTIGATIONS ON MODIFICATION OF BINDER SYSTEM IN INVESTMENT CASTING
}

\author{
Khyati Tamta $^{1}$, Umesh Wankhede ${ }^{2}$, D.B.Karunakar ${ }^{3}$ \\ ${ }^{1,2,3}$ Mechanical \& Industrial Engineering Department, IIT Roorkee, Uttarakhand, India 247667 \\ *Email: khyatitamta@gmail.com \\ ${ }^{*}$ Contact No.- +91-9528824833
}

\begin{abstract}
Investment casting process has been extensively used for ages. This process is also known as 'lost wax casting' or 'precision casting'. This casting process can produce extremely complex products with good dimensional accuracy and excellent surface finish. Due to environmental and economic pressure there is a need to improve casting quality and reduce manufacturing cost. Poor quality of the slurry ingredients lead to the poor quality of the casting. During dewaxing process, small cracks are likely to be developed in the ceramic shell because of the wax expansion and the poor mechanical properties of the shell. These cracks can be reduced by modifying the slurry ingredients. In the present work, an attempt is made to improve the strength of the ceramic shell. Fevicol was mixed with the binder of conventional slurry ingredients. Fevicol was added to the inner coat of the shell. It has a good binding property. Ceramic shell was prepared using both the slurries. Slurry and stucco retention property was measured for both shells. The addition of fevicol has improved the retention property of the shell as compared to the conventional shell.
\end{abstract}

Keywords: Investment Casting, Ceramic Shell, Fevicol, Retention Property.

\section{INTRODUCTION}

Investment casting process is widely known for its good surface finish and excellent dimensional accuracy [1]. Selection of coating material is very crucial for the preparation of ceramic shell. Poor selection of ingredients leads to the poor mechanical properties. During dewaxing process, small cracks can be developed in the ceramic shell because of the wax expansion. These cracks are developed due to the poor mechanical properties of the shell. These cracks can be reduced by modifying the slurry ingredients. In many foundries, water or alcohol based silica binder are used as the coating material. Alcohol based ethyl silicate binder has very limited use due to the environmental issues [2]. Shell containing water based colloidal silica binder has breakage tendency during removal of wax pattern because of very low green strength of the shell [3]. Organic fibres were added to the slurry ingredients to improve the shell thickness at the round edges and sharp corners. These fibres required very less resistance and forces while removal from the matrix [4]. Rice hull ash addition to the ceramic slurry ingredients had shown improved permeability along with improved thickness of the shell [5]. Further addition to this, Wang et al. have improved the shell thickness of the shell by adding needle coke to the outer layer of the shell. Modified shell had improved mechanical properties than conventional shell [6]. Camphor and needle coke was added to the ceramic slurry to improve the permeability and mechanical properties of the shell [7]. Slurry retention is the ability of ceramic slurry to adhere to the pattern to form ceramic shell. Micro cracks can be deveoped after drying the slurry to form shell if ceramic slurry does not have good retention property. Less retention of stucco causes the sticking of adjacent slurry layers, which causes the entrapment of gases while pouring because of the fine size of the slurry ingredients. These entrapped gases cause porosity defect in the solidified castings. In the present work, fevicol was added to the inner coat of the shell to improve the adhesive property of the slurry.

\section{MATERIALS AND METHODS}

Conventional ceramic slurry was prepared using aluminum silicate refractory powder, colloidal silica binder and zircon powder. Table 1 shows the proportions of the ingredients of conventional and modified slurry. Ingredients were mixed in an investment mixer and stirred for 24- 72 hours continuously. Wax pattern was dipped in the slurry and stucco was applied to avoid the adhesion of adjacent coat. Prepared pattern was dried in a controlled atmosphere for 24 hours to prepare the primary coat of the shell. Remaining coats were prepared in the same manner as the primary coat. For the modified shell, fevicol was added in the primary coat of the shell and prepared in the same manner as the conventional shell. Table 2 shows the details of the conventional and modified shell system.

Table 1: Proportions of ingredients of conventional ceramic slurry

\begin{tabular}{|c|c|c|}
\hline Ingredients & $\begin{array}{c}\text { Conventional } \\
\text { slurry }\end{array}$ & Modified slurry \\
\hline $\begin{array}{c}\text { Aluminium } \\
\text { silicate }\end{array}$ & $50 \%$ & $50 \%$ \\
\hline $\begin{array}{c}\text { Colloidal silica } \\
\text { binder }\end{array}$ & $40 \%$ & $40 \%$ \\
\hline Zircon powder & $5 \%$ & $5 \%$ \\
\hline Water & Few drops & Few drops \\
\hline Fevicol & - & $2 \%$ (inner coat) \\
\hline
\end{tabular}


Table 2: Details of conventional and modified shell systems

\begin{tabular}{|c|c|c|c|}
\hline $\begin{array}{c}\text { Shell } \\
\text { system }\end{array}$ & Coat & Slurry type & Stucco \\
\hline \multirow{3}{*}{$\begin{array}{c}\text { Convention } \\
\text { al slurry }\end{array}$} & 1 & Primary & Molochite 50/80 \\
\cline { 2 - 4 } & $2-5$ & Secondary & Molochite 16/30 \\
\hline \multirow{3}{*}{$\begin{array}{c}\text { Modified } \\
\text { slurry }\end{array}$} & 6 & Outer & n/a \\
\cline { 2 - 4 } & $2-5$ & Primary & Molochite 50/80 \\
\cline { 2 - 4 } & 6 & Outer & n/a \\
\hline
\end{tabular}

Wax pattern was drained out during dewaxing process and shell was fired to remove the wax residue and to provide strength to the shell. Slurry and stucco retention property was calculated for both the shell. Mircostrual analysis was also done to investigate the inner coat of the shell in both the cases.

\section{RESULT AND DISCUSSION}

Slurry and stucco retention measurement test was done using plate weight method. It was performed on metallic plate with the dimension of $150 * 50 * 10 \mathrm{~mm}$. Metallic plate was dipped inside the slurry and stucco coating and weight of undipped and dipped plate has been measured. Figures 1 and 2 show the retention with respect to the time of conventional and modified slurries and stucco on the metallic plate. Modification in the slurry ingredients has improved the slurry and stucco retention property as compared to the conventional slurry.

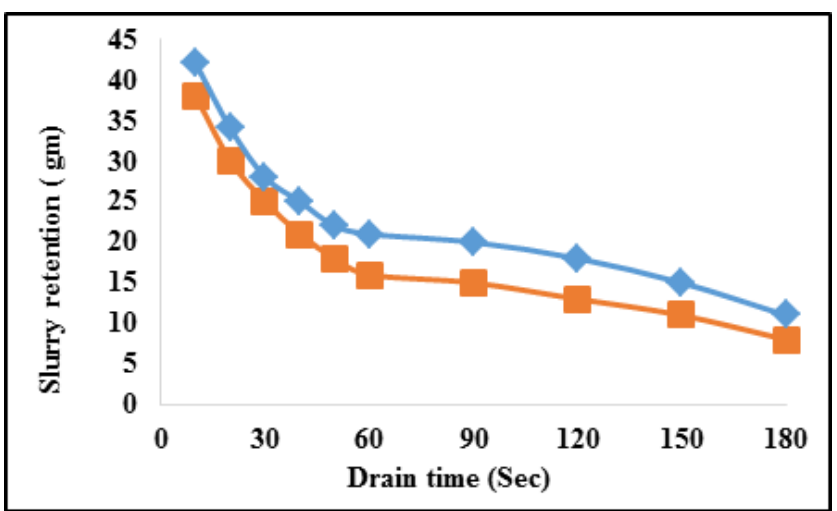

Figure 1: Retention of slurry for conventional and modified slurry ingredients

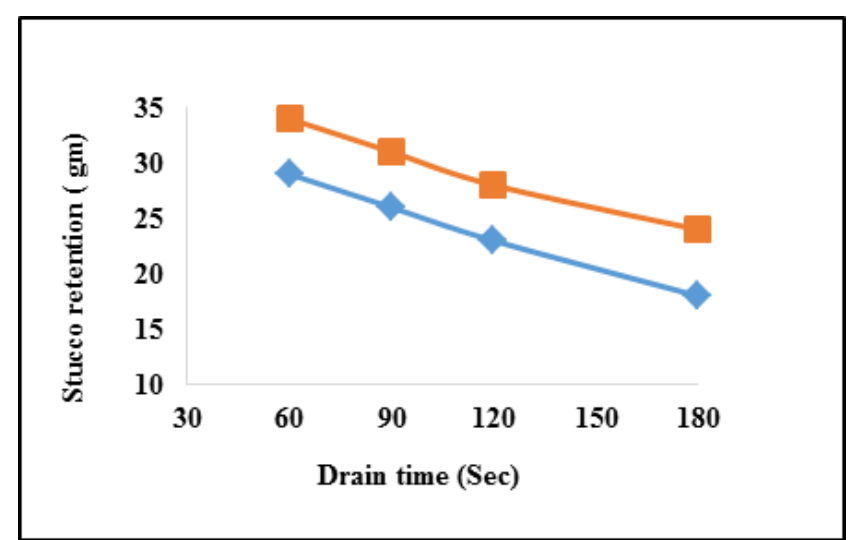

Figure 2: Retention of stucco for conventional and modified slurry ingredients

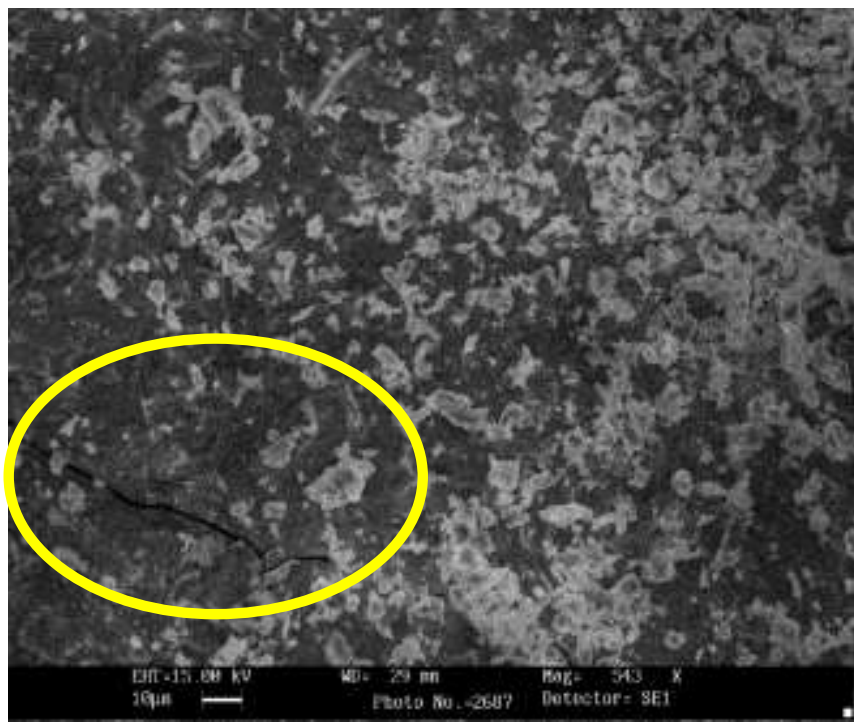

Figure 3. Microstructure of conventional shell

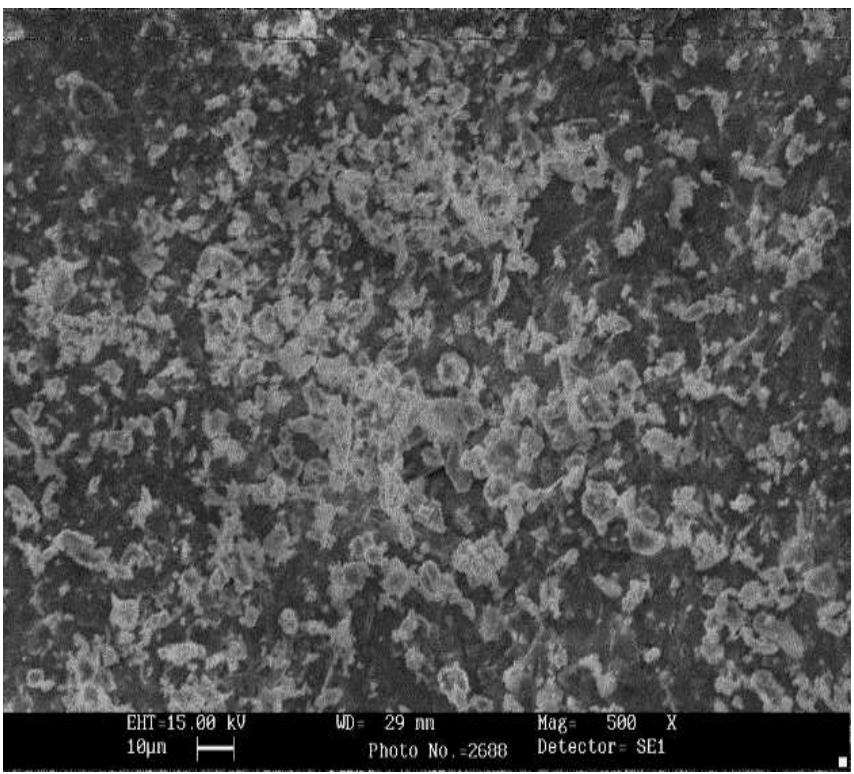

Figure 4. Microstructure of modified shell

Figures $3 \& 4$ show the microstructure of the shells. Scaning electron microscopy was used for the microstructure analysis. From the Figure 3, it can be seen that some cracks were developed in the conventional ceramic shell because of the poor retention of the slurry on the pattern. These developed cracks will affect the surface finish of the cast part. Addition of fevicol had prevented the formation of the micro cracks on the shell's inner coat by improving the slurry retention property of the shell. By this modification surface finish of the cast part can be improved.

\section{CONCLUSIONS}

In the study, an innovative modification was done in the binder system of the investment casting process. Addition of fevicol had improved the retention of slurry and stucco to the wax pattern. This modification had prevented the formation of micro cracks on the inner coat of the shell. 


\section{REFERENCES}

[1] Pattnaik, S., Karunakar, D.B., and Jha, P.K., 2012, "Developments in Investment Casting Process - A Review", Journal of Materials Processing Technology, Vol. 212.

[2] Jones, S., 1993, "Improved Sol Based Ceramic Moulds for Use in Investment Casting, Ph. D, Thesis", University of Birmingham, Edgbaston, UK.

[3] Jones, S., and Yuan, C., 2003, "Advances in Shell Moulding for Investment Casting", Journal of Materials Processing Technology, 135, 258-265.

[4] Yuan, C., Jones, S., and Blackburn, S., 2005, “The Influence of Autoclave Steam on Polymer and Organic Fibre Modified Ceramic Shells", Journal of the European Ceramic Society, 25, 1081-1087.

[5] Vandermeer, J., Buntrock, K. A., Branscomb, T.M., and David, A. G., "Investment casting shells and Compositions including Rice Hull Ash", U. S. Patent, 0252632 A1, filed, 2005.

[6] Wang, F., Li, F., He, B., and Sun, B., 2014, "Microstructure and Strength of Needle Coke Modified Ceramic Casting Moulds", Ceramics International, 40, 479-486.

[7] Tamta, K., Karunakar, D.B., 2014, "Enhancement of Porosity of the Ceramic Shell in Investment Casting Process Using Needle Coke and Camphor", Applied Mechanics and Materials, 592, 269-275. 